\title{
George Sand, Impressions et souvenirs
}

Aline Alquier

\section{(2) OpenEdition}

\section{Journals}

\section{Édition électronique}

URL : https://journals.openedition.org/studifrancesi/26562

DOI : 10.4000/studifrancesi.26562

ISSN : 2427-5856

\section{Éditeur}

Rosenberg \& Sellier

\section{Édition imprimée}

Date de publication : 1 avril 2007

Pagination : 196-197

ISSN : 0039-2944

\section{Référence électronique}

Aline Alquier, "George Sand, Impressions et souvenirs », Studi Francesi [En ligne], 151 (LI | I) | 2007, mis en ligne le 30 novembre 2015, consulté le 23 novembre 2021. URL : http://journals.openedition.org/ studifrancesi/26562 ; DOI : https://doi.org/10.4000/studifrancesi.26562

\section{Ce document a été généré automatiquement le 23 novembre 2021.}

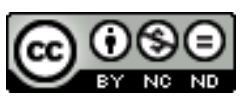

Studi Francesi è distribuita con Licenza Creative Commons Attribuzione - Non commerciale - Non opere derivate 4.0 Internazionale. 


\title{
George Sand, Impressions et souvenirs
}

\author{
Aline Alquier
}

\section{RÉFÉRENCE}

GEORGE SAND, Impressions et souvenirs, édition par Ève SOURIAN, avec la collaboration de Brigitte LANE, Paris, Éditions des Femmes / A.Fouque, 2005, pp. 337.

1 Des vingt-deux feuilletons de George Sand publiés par «Le Temps» d'août 1871 à janvier 1873, puis édités la même année par Michel Lévy sous le titre Impressions et souvenirs, Ève Sourian en a retenu quatorze dont elle apprécie le lyrisme fluide qui les imprègne.

Dans la préface et les textes présentant les feuilletons, elle met en relief la nouveauté d'une entreprise qui exprime "ce qui lui vient ou lui est venu en dehors de la fiction»; c'est du moins ce que Sand confie le 25 août 1871 à Charles-Edmond, alors président du conseil d'administration du journal. Les textes introductifs (treize d'E. Sourian, un de B. Lane) sont d'autant plus nécessaires qu'un certain nombre de feuilletons ont pour origine des notations glanées dans d'anciennes chroniques, de nouveau méditées par Sand avec dix ou vingt ans de recul.

3 Ce passé, restitué au premier feuilleton par une saisissante giclée d'odeurs et de couleurs, plonge le lecteur dans une nature généreuse où s'immerge la romancière dont le panthéisme à relents païens rappelle les idées de Novalis et de Schelling probablement transmises par Mme de Staël.

4 À l'occasion d'une remémoration par l'écrivain d'une escapade de jeunesse en forêt de Fontainebleau dans le feuilleton III, E. Sourian rapproche la conception sandienne de l'appréhension du moi par le monde extérieur de celle du néoplatonisme de la Renaissance allemande reprise par les romantiques d'outre-Rhin.

Bâti à partir de notes rédigées trente ans plus tôt, le «feuilleton peinture et musique»le préféré de l'écrivain - est depuis longtemps plus ou moins connu, même de ceux n'ayant pas eu accès à sa lecture. La préfacière met en relief la beauté de la conclusion musicale improvisée par Chopin («la note bleue») comme pour clore à sa manière le débat engagé par Delacroix sur l'essence de la couleur - thème récurrent au XIX ${ }^{\mathrm{e}}$ siècle. 
«Cet essai charmant, note la présentatrice, qui commence chez Delacroix pour finir par un dîner en famille chez George Sand se déroule comme une petite scène de théâtre».

À propos du texte VI, relatif à l'évolution des idées religieuses de l'auteur, E. Sourian rapproche la synthèse à laquelle Sand aspire entre raison et foi du désir de perfection et d'infini manifesté par Mme de Staël.

7 Les feuilletons VII et VIII, dédiés à François Rollinat, semblent faire écho à une notation de l'agenda sandien du 14 août 1867, à l'annonce de la mort de cet ami: «Nous causerons encore et toujours ensemble, tu m'entendras». Sand se reporte aux premiers mois de 1861: de longues semaines auparavant, frappée par la maladie, elle a vu la mort de près; la joie exprimée par les siens à sa sortie du délire l'a incitée à se replonger avec ardeur dans «cette courte vie». C'est dans cet état de convalescence émerveillée qu'elle invite son compagnon d'équipées berrichonnes à partager avec elle la beauté de la lumineuse Provence: elle tient à le faire témoin de l'écart notable qu'elle constate entre la vision de la beauté et le souvenir qui l'intensifie. Ève Sourian souligne la conscience qu'a Sand de «ce besoin de remaniement de la réalité qui s'effectue dans un état d'ivresse et d'hallucination et qui échappe à sa volonté». C'est seulement après être «rentrée» en elle-même qu'elle remanie et devient voyante. [...Le réel] ne peut être atteint qu'à l'intérieur de nous-mêmes dans l'inconscient». De cet inconscient surgissent les rêves. Ses derniers accès de fièvre en ont fait naître de bien étranges chez l'écrivain. Elle les évoque pour l'ami auprès de qui jadis elle a, dit-elle, «observé les phénomènes du sommeil, du délire et de l'hallucination». La préfacière, qui rapproche le nuage nacré du rêve de "fin du monde" de l'éclat immatériel de la géode où Laura prend place dans le roman qui, édité en 1863, porte son prénom, juge assez équilibré le dosage du merveilleux et de l'ébauche d'explication rationnelle du cauchemar. Par cette recherche des phénomènes de l'inconscient, l'auteur, estime E. Sourian, «rejoint les philosophes de la nature pour qui, par le rêve, l'âme est en étroite communauté avec l'univers».

Dans le texte X, daté du 20 août 1872 et intitulé L'Homme et la femme, Sand abandonne les retours au passé pour se glisser dans un débat masculin autour de la femme adultère, lancé en quelques semaines par un livre d'Henri d'Ideville, relayé par une brochure à succès de Dumas fils, puis par une lettre publiée par Girardin, conclu enfin par un pesant " examen " de la question à la lumière de la Bible, dû au Dr Favre. Pour sa part, Sand récuse la Bible comme modèle pour la mise en oeuvre de «la civilisation universelle», mais elle rejette d'un revers de main le divorce et autres réformes jadis évoquées dans ses romans premiers. Elle se satisfait d'en appeler, dans l'intérêt de «la progéniture» à l'amour censé tout arranger. Cette fois encore l'écrivain épuise son lyrisme à replacer les humains au coeur d'un monde végétal et animal où s'impose la nécessité de la reproduction. Mais la société n'a-t-elle pas d'autres lois moins angéliques? Le code civil en est une terrible pour les épouses. C'est ce que Dumas fils rappelle à Sand dans une lettre de janvier 1873 (inédite, elle est reproduite par E. Sourian d'après les archives de Christiane Sand) où il replace l'écrivain dans une position d'«enchaînée socialement, [...elle...] valeur de premier ordre, à cette valeur [...] encombrante que fut M. Dudevant».

Bien fournie, la bibliographie de cette nouvelle édition n'est pas exempte d'erreurs. L'ensemble est néanmoins des plus satisfaisants et permet une redécouverte éclairée de textes jalonnant la réflexion sandienne de la maturité. 